\title{
Research Article \\ Study on Mechanical Properties and Failure Mechanism of Axial Braided C/C Composite
}

\author{
Chunguang Wang $\mathbb{D}^{1}{ }^{1}$ Weiping Tian, ${ }^{2}$ and Min Tang ${ }^{2}$ \\ ${ }^{1}$ State Key Laboratory for Strength and Vibration of Mechanical Structures, School of Aerospace Engineering, \\ Xi'an Jiaotong University, Xi'an 710049, China \\ ${ }^{2}$ The Fourth Academy of CASC, Xi'an 710025, China
}

Correspondence should be addressed to Chunguang Wang; king19850723@163.com

Received 12 February 2020; Revised 10 July 2020; Accepted 10 August 2020; Published 4 February 2021

Academic Editor: Mohammad Tawfik

Copyright (c) 2021 Chunguang Wang et al. This is an open access article distributed under the Creative Commons Attribution License, which permits unrestricted use, distribution, and reproduction in any medium, provided the original work is properly cited.

\begin{abstract}
In order to study the mechanical properties and failure mechanism of the axial braided $\mathrm{C} / \mathrm{C}$ composites, the microscopic and macroscopic mechanical properties of the composite were investigated. In view of the size effect of the samples, the properties of the samples with different thickness were tested. The strain during loading was measured by optical method, and the failure morphology was observed by SEM. The changing characteristics of stress-strain curve were analyzed, and the failure characteristics of materials and failure mechanism under various loads were obtained. It was found that brittle fracture was observed during the tensile process of axial braided $\mathrm{C} / \mathrm{C}$ composites, and the main failure forms were fiber rod pulling and partial fiber rod breaking in the axial direction. Radial failure was mainly in the form of fiber bundle fracture and crack stratification propagation. When compressed, the material exhibited pseudoplastic characteristics. The radial compression sample was cut along a 45-degree bevel. The axial compression curve was in the form of double fold, the axial fiber rod was unstable, and the transverse fiber bundle was cut. During in-plane shearing, the axial fracture was brittle and the fiber rod was cut. The radial direction showed the fracture and pulling of the fiber bundle, and the material had the characteristics of pseudoplasticity. The research methods and results in this paper could provide important references for the optimization and rational application of $\mathrm{C} / \mathrm{C}$ composite materials.
\end{abstract}

\section{Introduction}

$\mathrm{C} / \mathrm{C}$ composite material is a carbon fiber reinforced carbon matrix composite material. The reinforcing phase and the matrix phase are both structural composites composed of pure carbon with special properties [1-4]. It has high specific strength, good thermal stability, wear resistance, ablative resistance, and a series of excellent properties, especially its mechanical properties with the increase of temperature strength does not fall but rise, so that it has been widely used in the aerospace field $[5,6]$. The macroscopic properties of $\mathrm{C} / \mathrm{C}$ composites are the essential pursuit of production research. Obtaining accurate material failure mechanism is the premise of improving material properties, and the corresponding material properties of the parameters are the basis of structural design $[7,8]$.
Researchers have conducted a large number of studies on the mechanical properties of $\mathrm{C} / \mathrm{C}$ composites and their components, mainly studying the strength $[9,10]$, modulus [11], damage evolution process [12], fracture properties [13], etc. These studies not only provide methods for understanding the intrinsic characteristics of $\mathrm{C} / \mathrm{C}$ composites, but also build a huge data base.

The C/C composites with similar structure mainly include direct braided and puncture $\mathrm{C} / \mathrm{C}$ composites, wound braided $\mathrm{C} / \mathrm{C}$ composites, three-dimensional four-way braided $\mathrm{C} / \mathrm{C}$ composites, multidimensional braided $\mathrm{C} / \mathrm{C}$ composites, and needled $\mathrm{C} / \mathrm{C}$ composites. The main results of the researches on its microscopic properties carried out by scholars are shown in Reference 1. From Reference 1, it can be found that the microscopic properties of $\mathrm{C} / \mathrm{C}$ composites have been studied a lot. However, due to the diversity of 
weaving methods, the complexity of production techniques, and the dispersion of research directions [14], no systematic research on mechanical properties and failure mechanism of $\mathrm{C} / \mathrm{C}$ composites has been found even after nearly 30 years of exploration [15-18].

In this paper, the mesoscopic and macroscopic mechanical properties and failure mechanism of axial braided $\mathrm{C} / \mathrm{C}$ composites were investigated. In order to study the size effect of samples, performance tests were carried out for samples of different thickness. The change of stress-strain curve and failure fracture characteristics were analyzed by means of optical strain measurement and SEM, and the failure characteristics, failure mechanism, and relevant data under various loads were obtained to provide references for the optimization and rational application of materials.

\section{Study on Mesoscopic Mechanical Properties of $\mathbf{C} / \mathbf{C}$ Composites}

The RVE of the axial braided C/C composite material is a rectangular structure composed of fiber rod, fiber bundle, matrix, and interface. The braided structure and phase scale of each component are shown in Figure 1. Thin carbon fiber rigid rod formed by pultrusion forms the axial reinforcing network, and the soft carbon fiber bundle is woven into the pretexture. The fiber rods are arranged in an equilateral triangle in the axial direction, and the fiber bundles are successively increased through the $0^{\circ}, 60^{\circ}$, and $120^{\circ}$ channels of cambium formed by the fiber rods, and so on until the required size of pretexture is formed. High-density $4 \mathrm{D} \mathrm{C} / \mathrm{C}$ composites are prepared by asphalt impregnation, carbonization, densification, and high-temperature treatment. The minimum unit of this pretexture is axially symmetric, and its braided thickness accumulates axially, so it is called axial braided $\mathrm{C} / \mathrm{C}$ composite.

According to the results of previous studies, it was found that the mechanical properties of fiber $\mathrm{rod}$ and fiber $\mathrm{rod} / \mathrm{ma}$ trix interface were the main influencing factors of the macroscopic properties of material [18]. Therefore, in terms of mesoscopic components, the above two aspects are mainly tested and studied.

2.1. Testing of Mechanical Properties of Fiber Rod. The reinforcing phase of the axial braided $\mathrm{C} / \mathrm{C}$ composite mainly consists of axial fiber rod and radial fiber bundle. Since the fiber bundle is loose polymerization before the composite, it is difficult to peel the composite fiber bundle. In this paper, only $z$-direction fiber rod is stripped. Firstly, a long strip sample containing only one group of $z$-direction fiber rod was obtained through mechanical processing, and then a complete $z$-direction fiber rod was obtained through manual processing. The remaining fiber bundles and matrix on the said long strip sample were stripped off with a blade. Figure 2(a) is the picture of the $z$-direction fiber rod after stripping.

2.1.1. Results of Tensile Loading. Figure 2(b) shows the tensile strain of the fiber rod at different moments. Since the extruded surface of the fiber rod is obviously deformed during the composite process and the damage is inevitably caused during the peeling process, the strain concentration of the fiber rod exists at different locations. After the loading to $150 \mathrm{~s}$, the surface paint powder of the sample falls off, resulting in subsequent strain loss.

Based on the strain obtained by ARMIS system (threedimensional optical strain measurement system), and combined with nominal stress-strain curve characteristics, the stress-strain curve of fiber rod failure was obtained, as shown in Figure 3(a). The tensile properties of the fiber rod are brittle. When the load reaches the maximum, the bearing capacity is quickly lost, which indicates that the fiber/matrix interface in the fiber rod has high bonding strength. Once the crack starts, it will quickly pass through the whole fiber rod, resulting in the fracture of the fiber rod.

The material properties of 15 fiber rods were obtained by tensile test, as shown in Table 1. These data show that the fiber rod after heat treatment has a great attenuation in strength and a great increase in modulus. The theoretical strength of T300 fiber filament and matrix composite should be higher than $1800 \mathrm{MPa}$, and the theoretical modulus is 130.4 GPa, while the measured average tensile strength of fiber rod is $760.4 \mathrm{MPa}$, and the tensile modulus is $211 \mathrm{GPa}$. The strength damage rate and modulus growth rates were $57.8 \%$ and $61.8 \%$, respectively. This change is mainly caused by the following three reasons.

(1) The graphitization degree of carbon fiber increases due to the graphitization temperature close to or higher than that at the time of manufacturing. The strength of the fiber rod will decrease, and the modulus will increase

(2) At high temperature, some volatile components in the material will overflow and the gas in the closed pore will expand, resulting in the increase of product porosity and the decrease of fiber rod strength and modulus

(3) Due to the mismatch between the thermal expansion coefficient of the matrix carbon and the fiber, as well as the influence of volatile gas, the fiber filament and the matrix carbon are debonding or the interface strength drops, resulting in the reduction of the fiber rod strength

The tensile failure morphology of the fiber rod is shown in Figure 3(b). From the microscale, the fracture plane of the fiber rod is uneven, and part of the fiber filament is pulled out of the matrix and broken, which is related to the deflection of the crack in the sample. In general, the interfacial bonding strength of the fiber and the matrix in rod is strong.

2.1.2. Results of Compression Loading. Figure 4(a) shows the experimental photos of fiber rod compression, while Figure 4(b) shows the failure mode after compression. The fracture of fiber rod shows a 45-degree incline, indicating that 

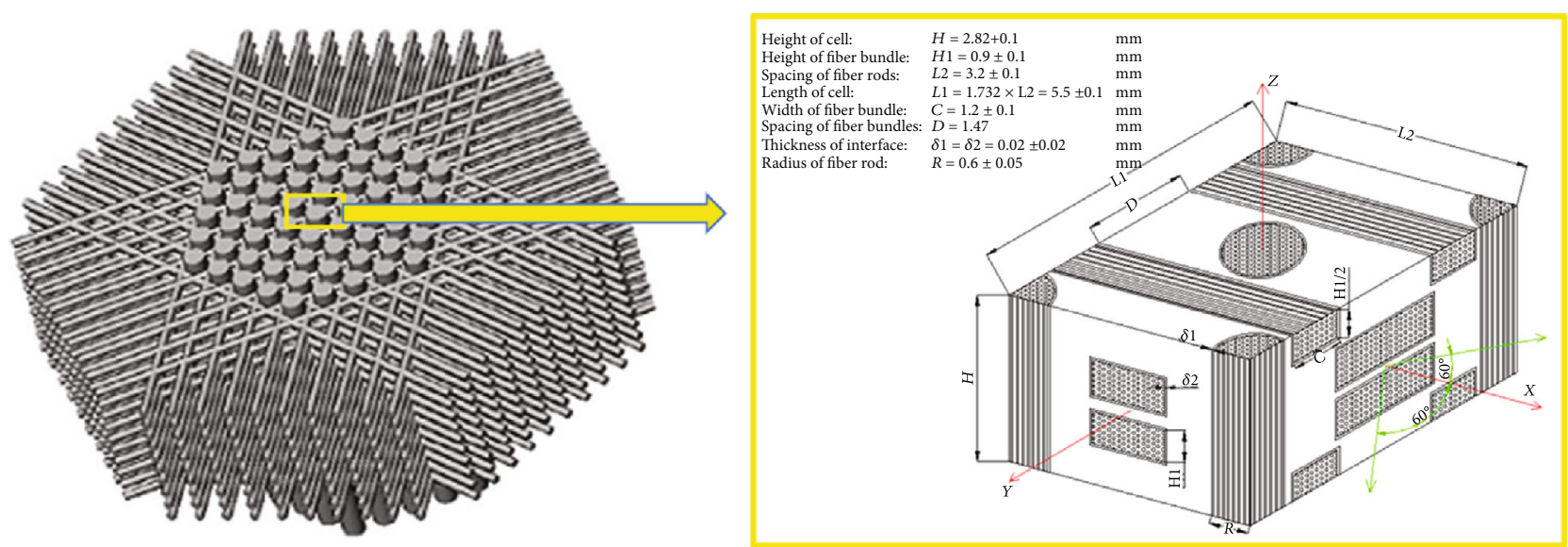

Figure 1: RVE of axial braided C/C composite.

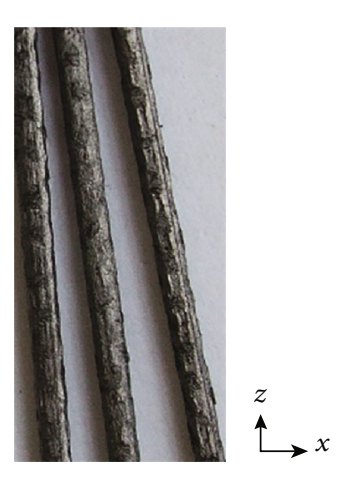

(a) Fiber rods

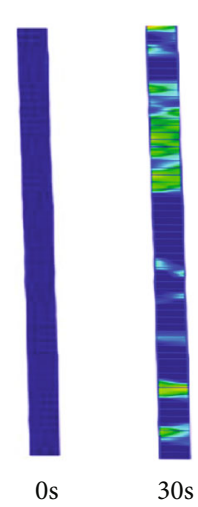

$30 \mathrm{~s}$

FIgURE 2: The strain test results of fiber rod during tensile process.

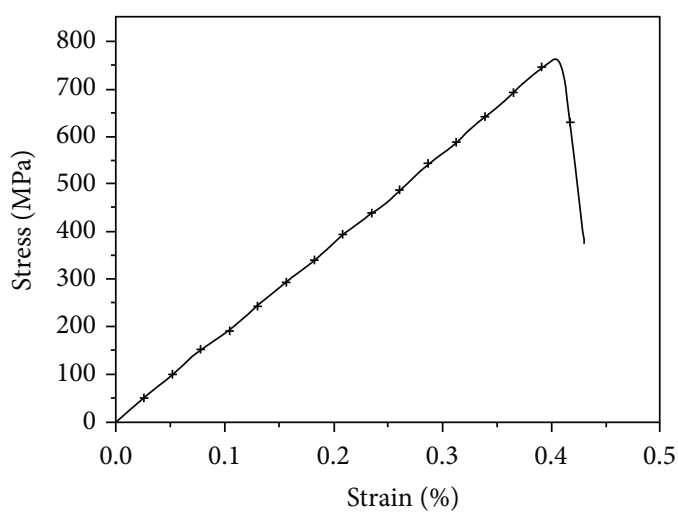

工 Fiber rod of material A

(a) Tensile stress-strain curve

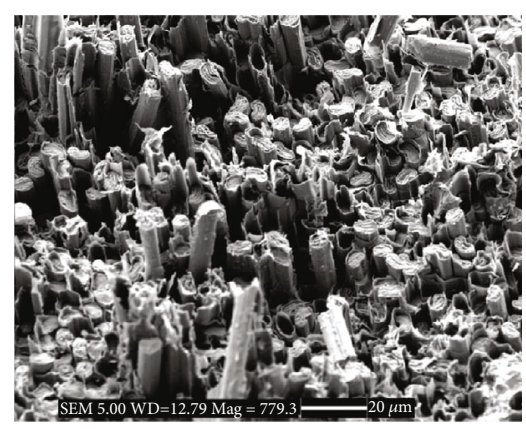

(b) The fracture morphology

Figure 3: Tensile stress-strain curve of fiber rod and fracture morphology after failure.

the compression failure of fiber rod is shear failure. Table 2 shows the compression properties of the fiber rod. The data show that the difference between the tensile strength and compression strength of the fiber rod decreases during the heat treatment process and is nearly equivalent. However, there is still a great difference in the tensile modulus and compression modulus of fiber rod, the former is 2.12 times of the latter. 
TABLE 1: Tensile properties of fiber rod.

\begin{tabular}{lccccc}
\hline \multicolumn{2}{c}{ Tensile strength, $\sigma_{1}^{T}(\mathrm{MPa})$} & \multicolumn{2}{c}{ Tensile modulus, $E_{1}^{T}(\mathrm{GPa})$} & \multicolumn{2}{c}{ Poisson's ratio $V_{13}$} \\
The average & The standard deviation & The average & The standard deviation & The average & The standard deviation \\
\hline 760.4 & 5.2 & 211.1 & 10.3 & 0.09 & 0.03 \\
\hline
\end{tabular}

Note: angle mark 1 represents the fiber rod axial direction, and angle mark $T$ represents the tensile condition.

2.1.3. Results of Shear Loading. The longitudinal shear and transverse shear properties of the fiber rod are performed by the experimental fixture shown in Figure 5. The core of the former is a load applied to half of the fiber rod to cause shear deformation along the symmetrical plane, while the core of the latter is bilateral shear.

Table 3 shows the shear properties of the fiber rod. Due to the limitation of the fixture, the shear strain is difficult to measure, so the nominal strain is adopted as the real strain. Combined with Tables 1 and 2, it can be found that the tensile, compression, and shear properties of fiber rods after heat treatment still show the characteristics of transverse isotropy, and at the same time show the properties of different modulus of tension and compression.

2.2. Experimental Study on Shear Properties of Fiber Rod/Matrix Interface. At present, there are two main methods used to characterize the shear strength of composite fiber rod/matrix interface: the fiber rod ejection method and the pull-out method. Since $\mathrm{C} / \mathrm{C}$ materials are brittle and prone to slip during clamping, the pull-out method is not suitable for characterization of the fiber rod/matrix interface properties of $\mathrm{C} / \mathrm{C}$ composites. Therefore, the fiber rod ejection method is adopted in this paper to characterize the interfacial shear strength of axial braided $\mathrm{C} / \mathrm{C}$ composites.

From the perspective of the existing interface characterization technology, the interface characterization of composites with different braiding parameters and sintering process is slightly different, and the main difference lies in the determination of interface test samples. In this paper, the thickness of the sample is several times of the diameter of the fiber $\operatorname{rod}(\Phi 1.1 \mathrm{~mm})$. They are 1.5 times $(1.65 \mathrm{~mm})$, 2 times $(2.2 \mathrm{~mm}), 2.5$ times $(2.75 \mathrm{~mm}), 3$ times $(3.3 \mathrm{~mm})$, 3.5 times $(3.85 \mathrm{~mm}), 4$ times $(4.4 \mathrm{~mm})$, and 4.5 times $(4.95 \mathrm{~mm})$, respectively.

The fiber rod ejection experiment was carried out for axial braided $\mathrm{C} / \mathrm{C}$ materials, and each sample ejection fiber rod was 30. The relationship between the sample thickness obtained through data analysis and the measured interfacial shear strength is shown in Figure 6. With the increase of sample thickness, interfacial shear strength can be divided into three stages. The analysis shows that when the sample is relatively thin (less than $3.85 \mathrm{~mm}$ ), the interface damage caused by processing is relatively large, and the measured interface strength is less than the real strength. When the sample is thicker (greater than $4.4 \mathrm{~mm}$ ), it is difficult to guarantee the perpendicularity of the fiber rod axis and the surface of the sample, so the measured strength not only includes the interfacial shear strength but also includes the transverse compression strength of the fiber rod. Therefore, $4.4 \mathrm{~mm} \mathrm{(4}$ times the thickness of the fiber rod) is appropriate for the interfacial shear strength test of the axial braided $\mathrm{C} / \mathrm{C}$ composite material. The measured shear strength of the fiber $\mathrm{rod} /$ matrix interface is normally distributed, and the mean and variance are 9.7 $\mathrm{MPa}$ and 2.1, respectively.

2.3. Experimental Study on Mechanical Properties of Matrix. There are many researches on the performance of the matrix, so it is not the focus of this paper. The axial braided $\mathrm{C} / \mathrm{C}$ composite matrix was tested by nanoindentation experiment. The results show that under the confidence interval of 0.95 , the elastic modulus of the matrix is between $12.04 \mathrm{GPa}$ and $12.68 \mathrm{GPa}$, and the average modulus of 12 measurements is $12.34 \mathrm{GPa}$.

\section{Study on the Macroscopic Mechanical Properties of $\mathbf{C} / \mathrm{C}$ Composite}

In engineering practice, the tensile, compression and shear properties of the materials are mainly concerned. In this paper, the above three aspects of the axial braided $\mathrm{C} / \mathrm{C}$ composite materials were tested and studied to obtain the mechanical properties and failure forms of the materials, and their failure mechanism was analyzed.

3.1. Uniaxial Tensile Test of Axial Braided C/C Composite. According to the weaving method of the material and the size of the product, three specimens of thickness are designed: $4.8 \mathrm{~mm}, 6.4 \mathrm{~mm}$, and $8.0 \mathrm{~mm}$. In the $z$-direction sample, it is strictly ensured that the fiber rod runs through the whole sample and the included angle between the fiber rod and the center axis is no more than $6^{\circ}$.

3.1.1. Radial Tensile. Figure 7 shows the radial tensile test results. As can be seen from the tensile strain cloud diagram (Figure 7(a)), the crack first started at the weak point of the matrix surface, which was generally at the junction of the fiber bundle and the matrix. With the increase of strain, the crack expanded along the surface of the fiber bundle and eventually led to failure. Further photomicrograph (Figure 7(b)) showed that the interface caused the crack to deflect, and the crack expanded in a step along the thickness. SEM photo (Figure $7(\mathrm{~d})$ ) of the radial fracture showed that the fiber bundle was completely pulled off, accompanied by the splitting of the fiber rod and the matrix, indicating that the fiber bundle was strongly interfacial with the surrounding matrix. The radial tensile stress-strain curve is shown in Figure 7(c). The specimens of different thickness show basically the same mechanical properties. The radial tensile shows the characteristics of brittle fracture. It is worth noting that when the strain reaches about $0.11 \%$, the modulus of the material shows great attenuation, which may be caused by matrix fracture. 


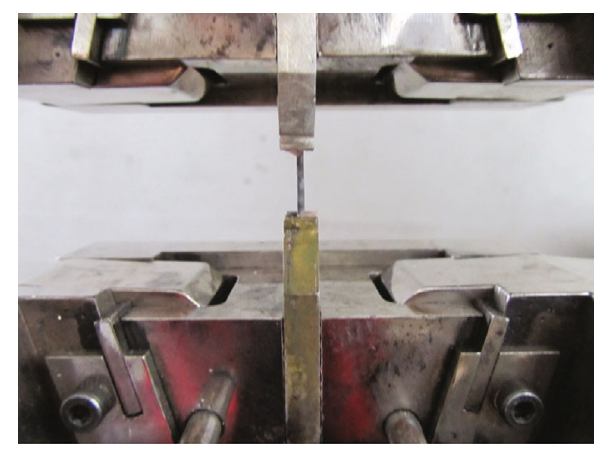

(a) Compression test

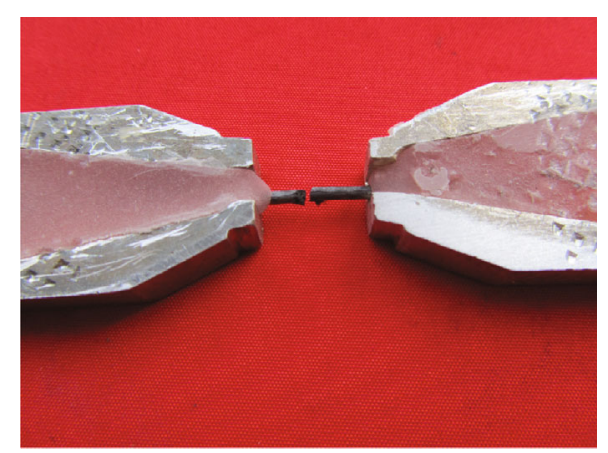

(b) Failure mode

Figure 4: Fiber rod compression experiment and failure mode.

TABLE 2: Longitudinal compression properties of fiber rod.

\begin{tabular}{lccccc}
\hline \multicolumn{2}{c}{ Compression strength, $\sigma_{1}^{C}(\mathrm{MPa})$} & \multicolumn{2}{c}{ Compression modulus, $E_{1}^{C}(\mathrm{GPa})$} & \multicolumn{2}{c}{ Poisson's ratio $V_{13}$} \\
The average & The standard deviation & The average & The standard deviation & The average & The standard deviation \\
\hline 897 & 63.7 & 99.4 & 8.47 & 0.15 & 0.03 \\
\hline
\end{tabular}

Note: angle mark 1 represents the fiber rod axial direction, and angle mark $C$ represents the compression condition.

3.1.2. Axial Tensile. Figure 8 shows the axial tensile test results. As can be seen from the tensile strain cloud diagram (Figure 8(a)), the crack extends along the interlayer interface of the fiber bundle, causing the separation of adjacent fiber bundles. Then, the interface between the axial fiber rod and the matrix is destroyed, so that the fiber rod is pulled out of the matrix, accompanied by the fracture of some fiber rods. In the micrograph (Figure $8(\mathrm{~b})$ ) of the axial fracture position, the failure of the fiber rod is shown as pulling out. SEM photo (Figure $8(d)$ ) of axial fracture showed that the fiber rod was pulled out during axial tensile, indicating that the fiber rod and the matrix were weakly interfacial. The axial tensile stress-strain curve is shown in Figure 8(c), which shows that the fiber rod breaks successively. When the load reaches the maximum value, the sample breaks completely and the load drops rapidly, but the sample still has a certain bearing capacity, which should be caused by the contribution of the interface to the overall strength.

The statistics of tensile test results are shown in Table 4. It can be seen from Table 4 that the $X$ (radial) tensile strength of the material is slightly higher than the $Z$ (axial) tensile strength, while the $X$ modulus is slightly lower than the $Z$ modulus. The main reason is that the fiber rod is weakly interfacial with the matrix, while the fiber bundle is strongly interfacial with the matrix, resulting in slightly higher radial tensile strength of the material.

3.2. Uniaxial Compression Test of Axial Braided C/C Composite. The radial and axial compression specimens were cuboids, and the length of the specimen was twice the length of the side of the section. The minimum side length of the section was $10 \mathrm{~mm}, 12 \mathrm{~mm}$, and $14 \mathrm{~mm}$, respectively.

3.2.1. The Radial Compression. Figure 9 shows the radial compression test results of axial braided $\mathrm{C} / \mathrm{C}$ composites.
The strain cloud diagram of the sample range during the compression experiment is shown in Figure 8(a). Under compression, the strain distribution is extremely uneven, and the strain concentration appears in the place where the fiber rod is arranged, which reflects the heterogeneity and anisotropy of the material. Figure 9(b) shows the failure morphology of radial compression. Radial compression is broken along a $45^{\circ}$ inclined plane, and the crack extends along the interlayer of fiber bundles. The compressive stress-strain curve is shown in Figure 9(c). The stress-strain variation trend of samples of three sizes is the same, showing the characteristics of pseudoplastic failure.

3.2.2. Axial Compression. Figure 10 shows the compression test results of axial braided $\mathrm{C} / \mathrm{C}$ composite materials. The strain cloud diagram of the sample range during the experiment is shown in Figure 9(a). The strain concentration occurs where the fiber bundles pass through the sample. Axial compression is destroyed along the $30^{\circ}$ inclined plane (Figure 10(b)), the matrix is crushed, the fiber bundle is cut along the failure plane, and the fiber rod and the matrix are debonded, indicating that the axial compression strength is controlled by the fiber rod, fiber bundle, and matrix. The stress-strain curve of axial compression is shown in Figure 10(c), and the stress-strain variation trend of samples of three sizes is the same, showing the characteristics of pseudoplastic failure. In addition, the axial compression curve shows the characteristics of doublefold line. It may be caused by the weak interface between the fiber rod and the matrix.

The statistics of compression test results are shown in Table 5. It can be found from the table that the compressive strength of the axial braided $\mathrm{C} / \mathrm{C}$ composite material is higher than the tensile strength, but the modulus is much lower. The larger the section size, the higher the strength. 


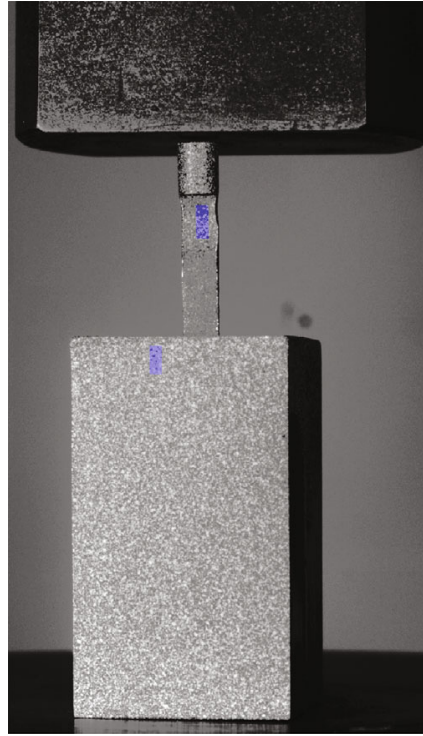

(a) Longitudinal shear

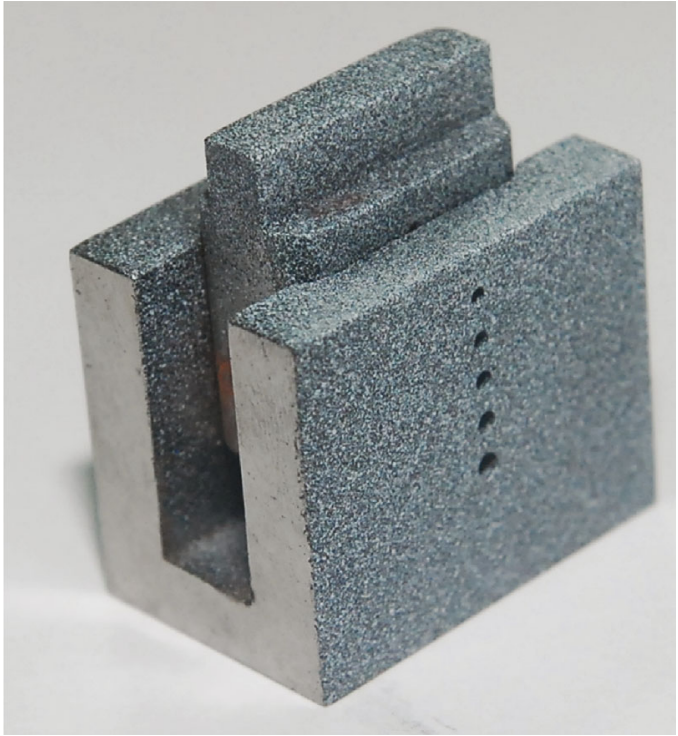

(b) Transverse shear

FIGURE 5: Fiber rod longitudinal shear and transverse shear test fixture.

TABLE 3: Shear properties of fiber rod.

\begin{tabular}{|c|c|c|c|c|c|c|c|}
\hline \multicolumn{2}{|c|}{$\sigma_{12}=\sigma_{13}(\mathrm{MPa})$} & \multicolumn{2}{|c|}{$G_{12}=G_{13}(\mathrm{GPa})$} & \multicolumn{2}{|c|}{$\overline{\sigma_{23}(\mathrm{MPa})}$} & \multicolumn{2}{|c|}{$G_{23}(\mathrm{GPa})$} \\
\hline $\begin{array}{l}\text { The } \\
\text { average }\end{array}$ & $\begin{array}{c}\text { The standard } \\
\text { deviation }\end{array}$ & $\begin{array}{l}\text { The } \\
\text { average }\end{array}$ & $\begin{array}{c}\text { The standard } \\
\text { deviation }\end{array}$ & $\begin{array}{l}\text { The } \\
\text { average }\end{array}$ & $\begin{array}{c}\text { The standard } \\
\text { deviation }\end{array}$ & $\begin{array}{l}\text { The } \\
\text { average }\end{array}$ & $\begin{array}{c}\text { The standard } \\
\text { deviation }\end{array}$ \\
\hline 35.2 & 3.1 & 22.6 & 1.2 & 49.8 & 2.67 & 7.2 & 2.3 \\
\hline
\end{tabular}

Note: angle mark 1 represents the fiber rod axial direction, and angle marks 2 and 3 represent the transverse direction.

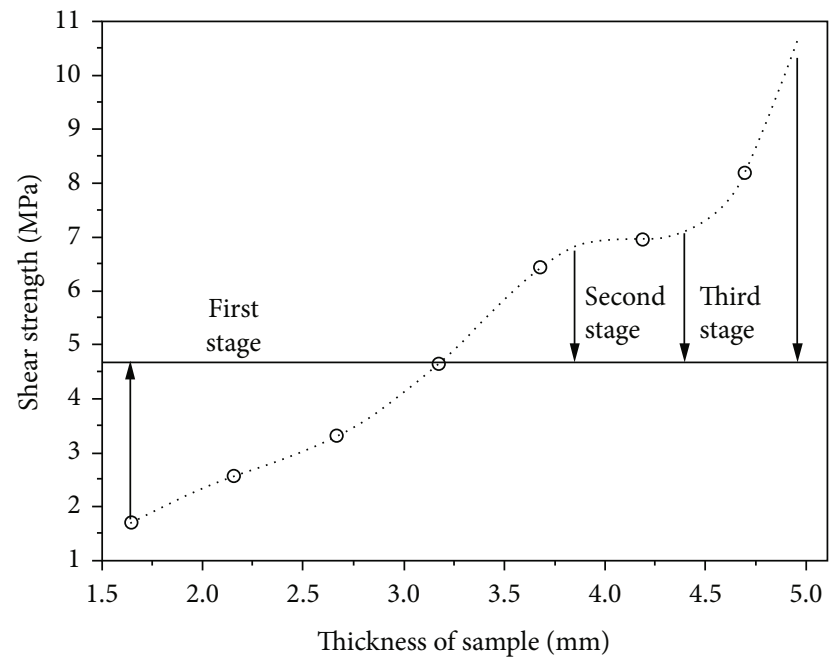

FIGURE 6: The relationship between specimen thickness and interfacial shear strength.

Axial compression strength is higher than radial compression strength, and the modulus of both is close. The main reason is that the hard fiber rod and matrix are combined in the axial direction, while the soft fiber bundle is combined in the radial direction. When loaded axially, the fiber rod and the matrix share the load of the matrix. When loaded radially, the fiber bundle could not share the load of the matrix. Therefore, the axial direction of the material has a greater bearing capacity than the radial direction.

3.3. In-Plane Shear Test of Axial Braided C/C Composite. Both radial $(X Y)$ and axial $(X Z)$ shear specimens were butterfly shaped, with thickness of $3.2,4.0$, and $4.8 \mathrm{~mm}$, respectively.

Figure 11(a) shows the failure mode of radial shear. It could be found that the fiber bundle is cut with a small amount of pulling out at the same time. The stress-strain curve (Figure 11(b)) is similar to the plastic feature, which is caused by the strong interfacial combination between the fiber bundle and the matrix. Figure 11(c) shows the failure form of axial shear. The fiber rod is cut, and the sample shows brittle failure. The corresponding stress-strain curve (Figure 11(d)) shows that the bearing capacity of the material decreases rapidly after reaching the ultimate load.

The statistics of shear test results are shown in Table 6. The shear strength increases with the increase of sample thickness, while the relationship between shear modulus and sample thickness is not obvious. This should be because when the sample is thin, the edge damage caused by processing is larger. 
(\%)

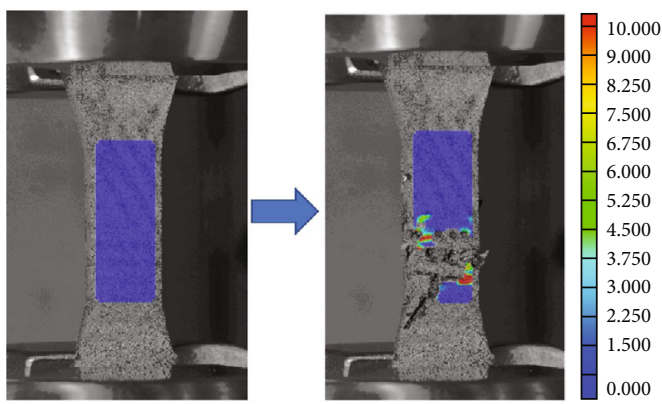

(a) Stretch strain
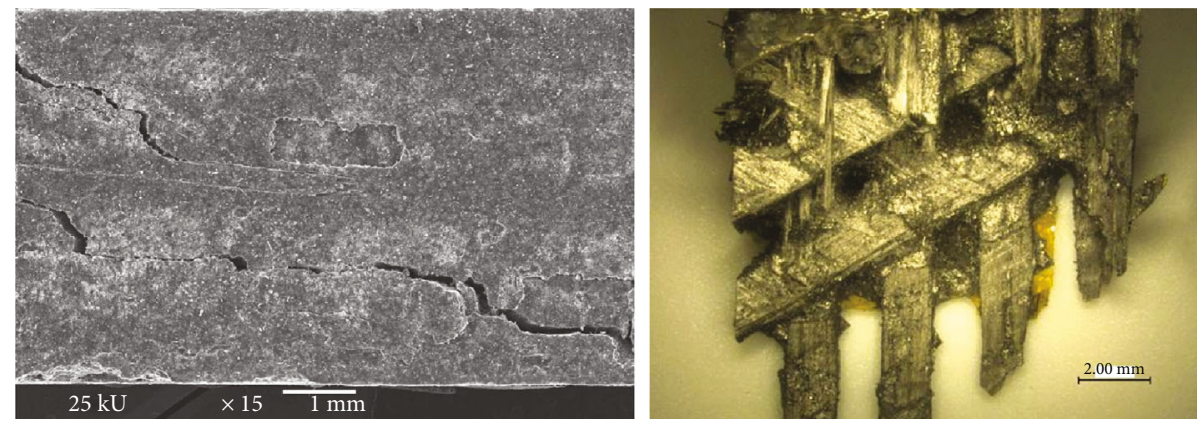

(b) Radial tensile failure mode

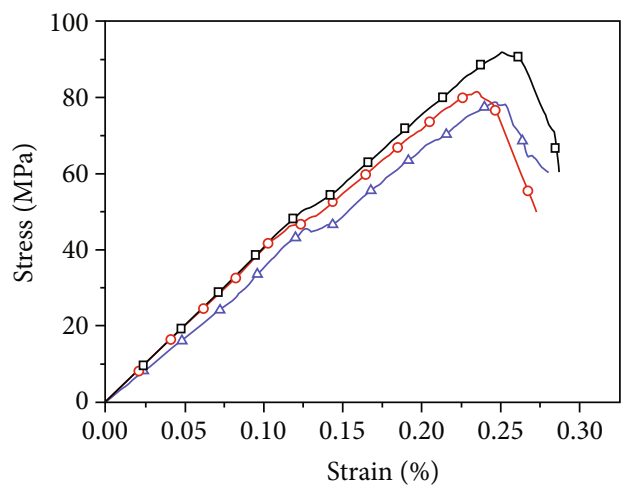

$$
\begin{aligned}
\longrightarrow & \mathrm{H} 1=8.0 \mathrm{~mm} \\
\multimap & \mathrm{H} 2=6.4 \mathrm{~mm} \\
\multimap & \mathrm{H} 3=4.8 \mathrm{~mm}
\end{aligned}
$$

(c) Radial tensile stress-strain curve
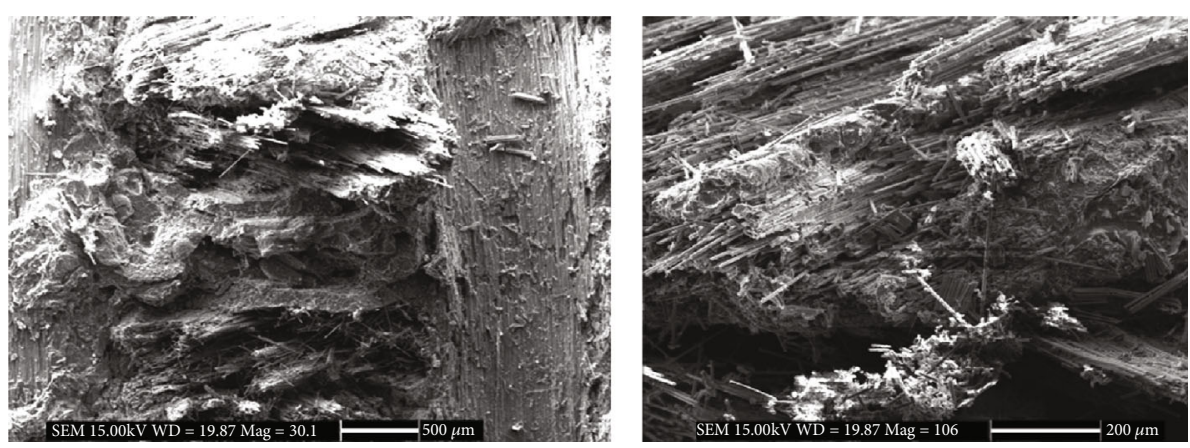

(d) SEM of radial fracture

Figure 7: Radial tensile test results. 


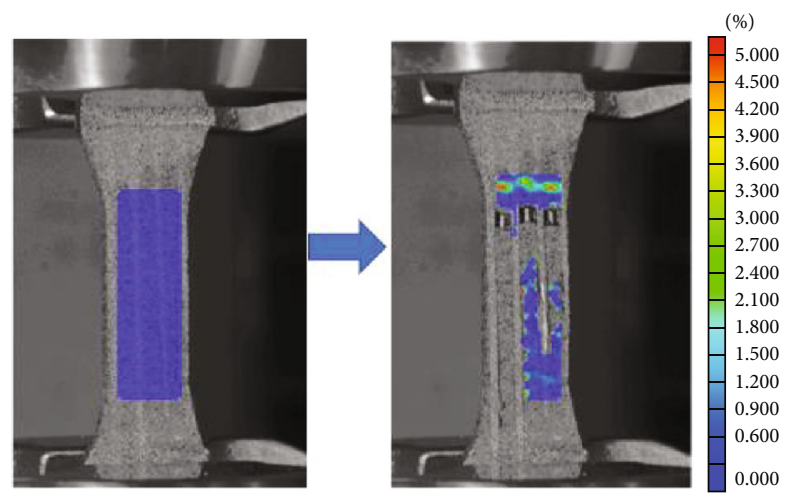

(a) Stretch strain
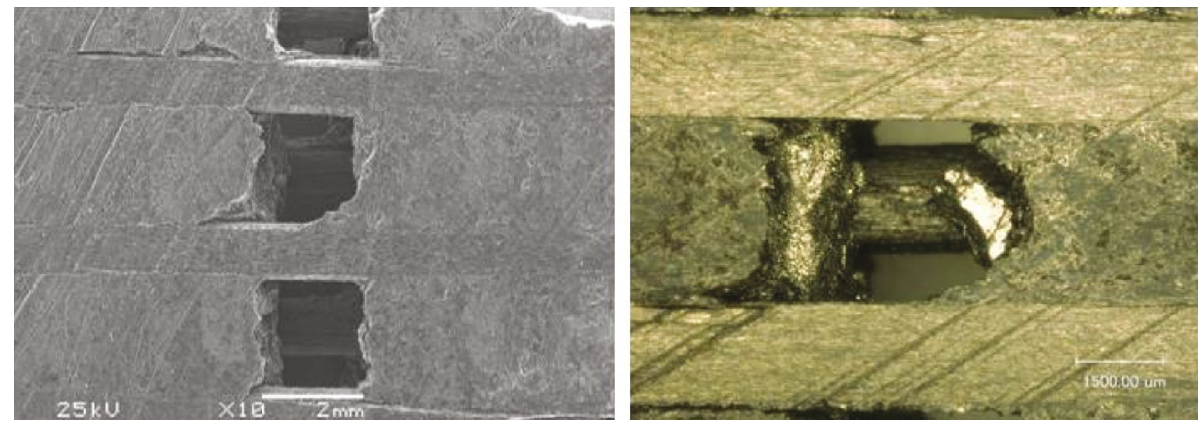

(b) Axial tensile failure mode

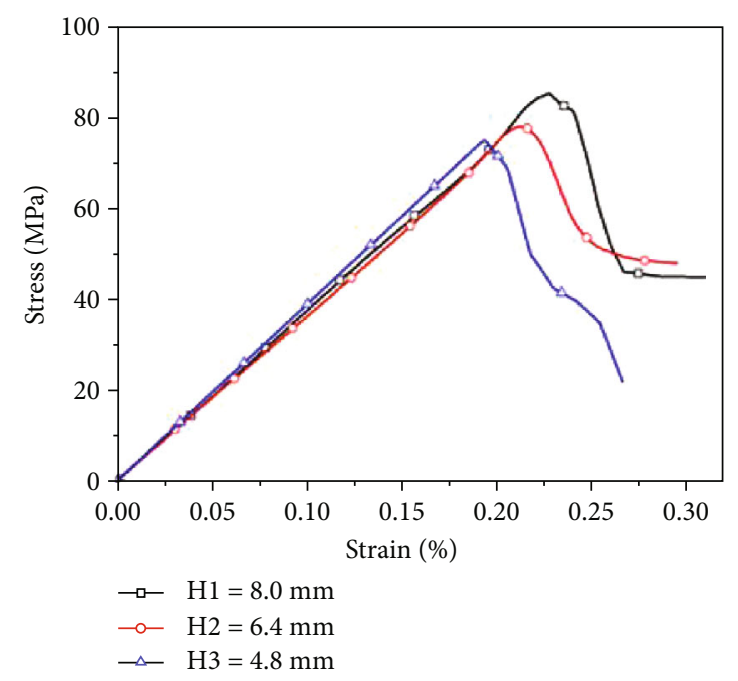

(c) Axial tensile stress-strain curve
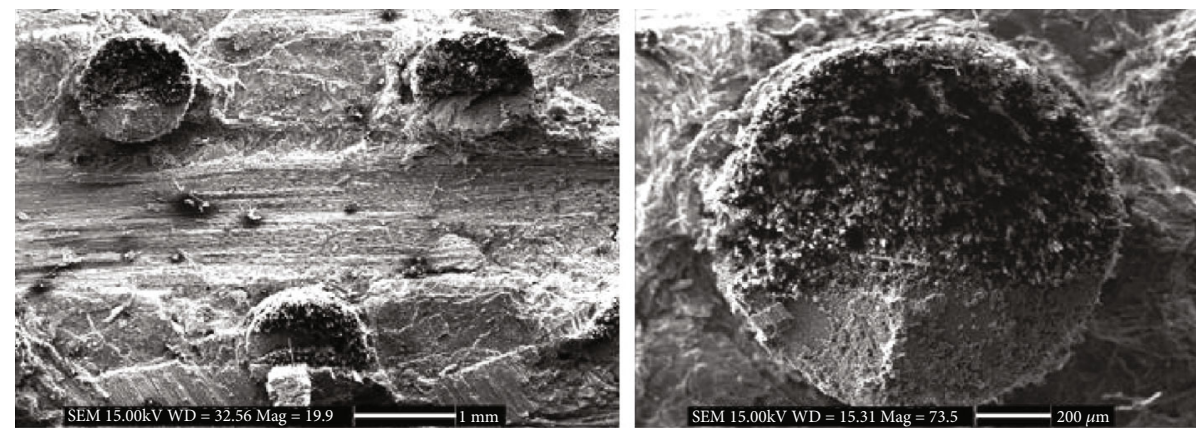

(d) SEM of axial fracture

Figure 8: Axial tensile test results. 
TABLE 4: Tensile mechanical properties of axial braided C/C composites.

\begin{tabular}{lcccccr}
\hline Specimen number & $\sigma_{X}^{t},(\mathrm{MPa})$ & $E_{X}^{t},(\mathrm{GPa})$ & $v_{X Y}^{t}$ & Specimen number & $\sigma_{Z}^{t},(\mathrm{MPa})$ & $E_{Z}^{t},(\mathrm{GPa})$ \\
\hline XT80 & 90.4 & 38.3 & 0.28 & $v_{Z X}^{t}$ \\
XT64 & 81.1 & 35.6 & 0.26 & ZT80 & 85.2 & 40.5 \\
XT48 & 78.1 & 37.1 & 0.26 & ZT64 & 78.1 & 37.8 \\
\hline
\end{tabular}

Note: angle mark $Z$ represents the fiber rod axial direction, angle marks $X$ and $Y$ represent the radial direction, and angle mark $T$ represents the tensile condition.

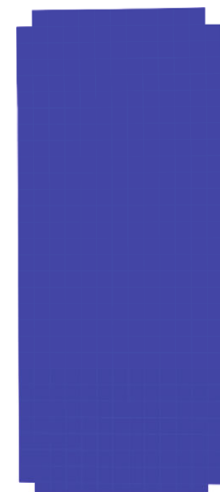

$0 \mathrm{~s}$

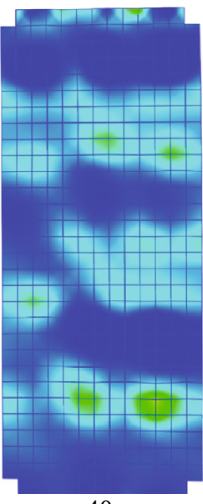

$40 \mathrm{~s}$

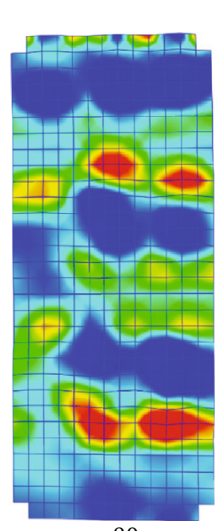

80 s

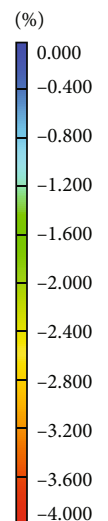

(a) Compressive strain

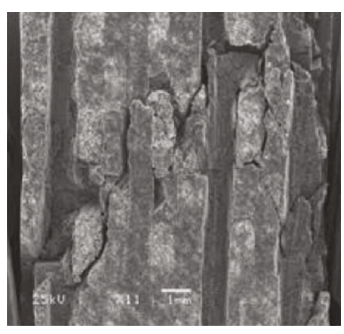

(b) Radial compressive failure mode

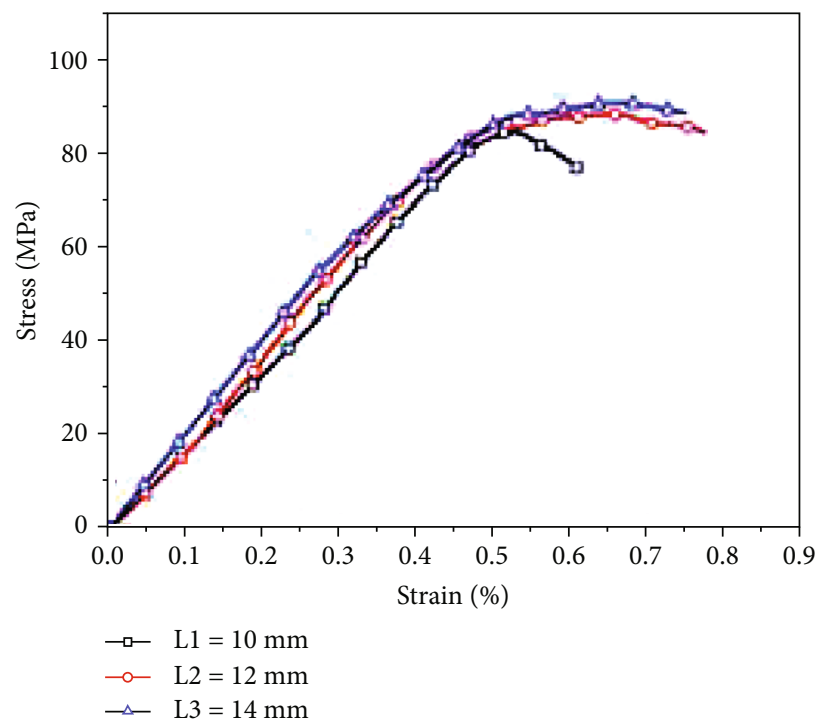

(c) Radial compressive stress-strain curve

Figure 9: Radial compression test results.

\section{Conclusion}

In this paper, macroscopic and mesoscopic mechanical properties of axial braided $\mathrm{C} / \mathrm{C}$ composites and their components were tested. The mechanical properties of the components and the whole were obtained, and the related mechanical properties and failure mechanism of the materials were obtained. The main conclusions are as follows:
(1) Under the action of tensile load, the fiber rod presents brittle fracture failure, and the failure section indicates that the fiber rod has strong interfacial bonding of filament/matrix. Under compression load, the fiber rod is shear failure. The longitudinal tensile strength and compressive strength of the fiber rod are $760.4 \mathrm{MPa}$ and $897.0 \mathrm{MPa}$, respectively. The corresponding modulus and Poisson's ratio are $211.1 \mathrm{GPa} / 0.09$, $99.4 \mathrm{GPa} / 0.15$, respectively, and the mean values of 


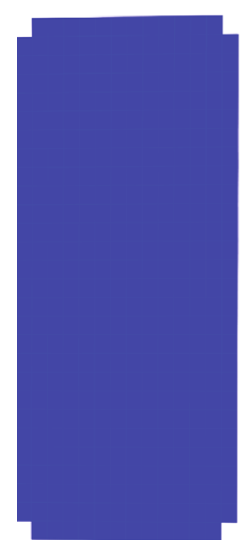

$0 \mathrm{~s}$

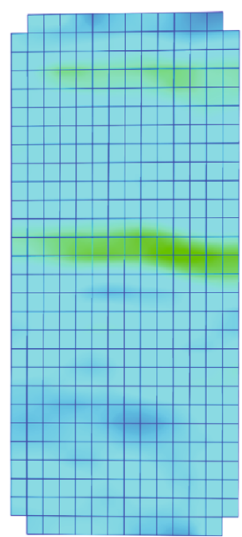

$40 \mathrm{~s}$

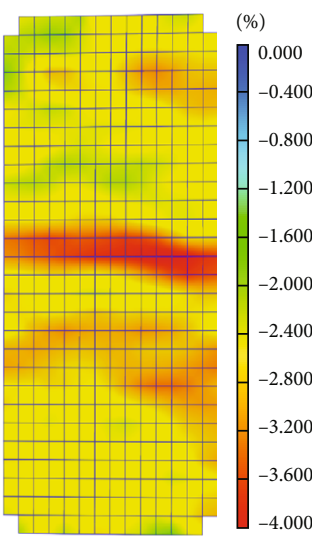

$80 \mathrm{~s}$

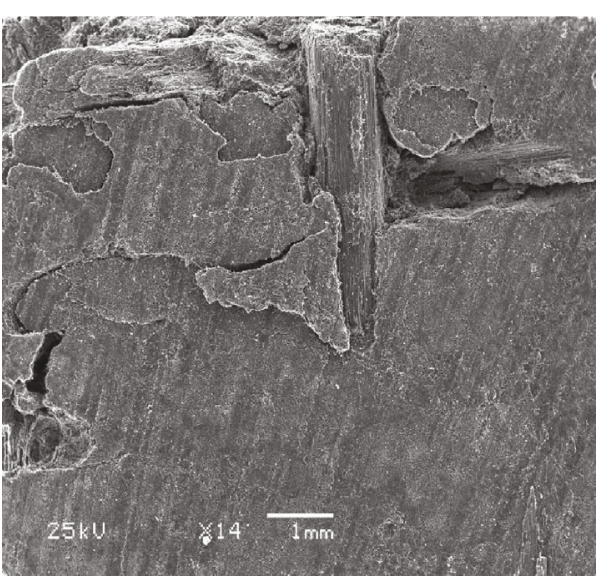

(b) Axial compressive failure mode

(a) Compressive strain

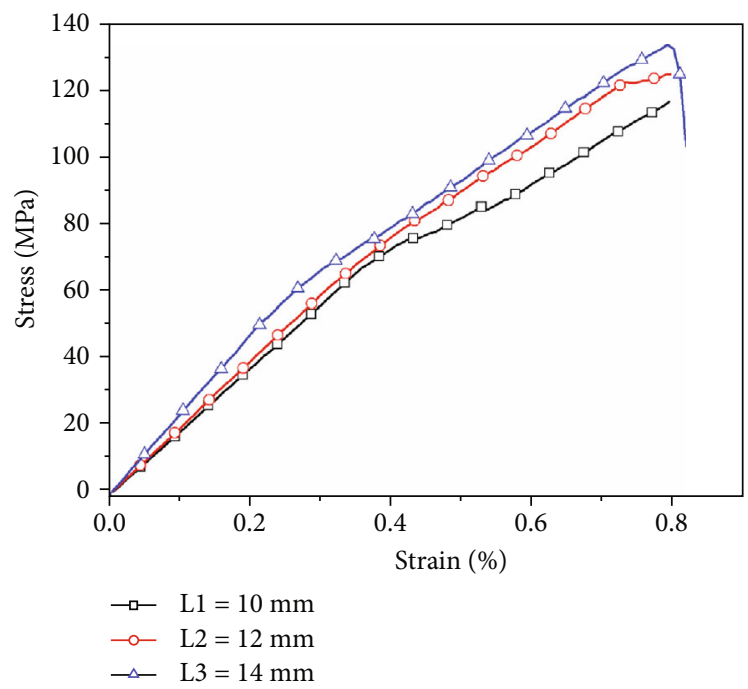

(c) Axial compressive stress-strain curve

Figure 10: Axial compression test results.

TABLE 5: Compression mechanical properties of axial braided C/C composites.

\begin{tabular}{lccccccr}
\hline Specimen number & $\sigma_{X}^{C},(\mathrm{MPa})$ & $E_{X}^{C},(\mathrm{GPa})$ & $v_{X Y}^{\mathrm{C}}$ & Specimen number & $\sigma_{Z}^{C},(\mathrm{MPa})$ & $E_{Z}^{C},(\mathrm{GPa})$ & $v_{Z X}^{C}$ \\
\hline XC14 & 90.6 & 20.9 & 0.28 & ZC14 & 132.5 & 22.1 & 0.09 \\
XC12 & 88.8 & 18.5 & 0.26 & ZC12 & 123.7 & 20.2 & 0.07 \\
XC10 & 84.5 & 17.0 & 0.26 & ZC10 & 116.7 & 21.1 & 0.07 \\
\hline
\end{tabular}

Note: angle mark $Z$ represents the fiber rod axial direction, angle marks $X$ and $Y$ represent the radial direction, and angle mark $C$ represents the compression condition.

longitudinal shear strength and transverse shear strength are 35.2 $\mathrm{MPa}$ and 49.8 $\mathrm{MPa}$, respectively

(2) For the test sample thickness of interfacial shear strength of fiber rod/matrix, it is appropriate to take 4 times diameter of fiber rod $(4.4 \mathrm{~mm})$, and the average interfacial shear strength is $9.7 \mathrm{MPa}$

(3) When the axial braided $\mathrm{C} / \mathrm{C}$ composite material is stretched, it shows the characteristic of brittle frac- ture. rThe main failure forms in axial direction are fiber rod pulling and part of fiber rod breaking. Radial failure is mainly in the form of fiber bundle fracture and crack stratification propagation. The adial tensile strength, modulus, and Poisson's ratio of axial braided $\mathrm{C} / \mathrm{C}$ composites are $90.4 \mathrm{MPa}$, $38.3 \mathrm{GPa}, 0.28$, and the corresponding axial tensile strength, modulus and Poisson's ratio are $85.2 \mathrm{MPa}$, $40.5 \mathrm{GPa}$, and 0.09 , respectively 


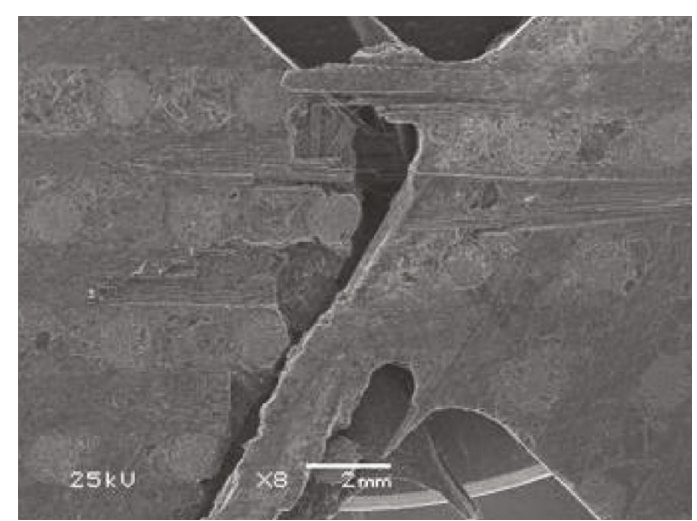

(a) Radial shear failure mode

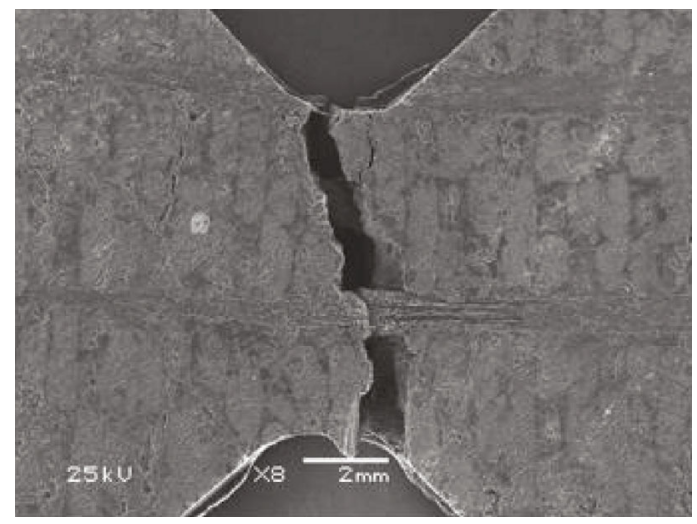

(c) Axial shear failure mode

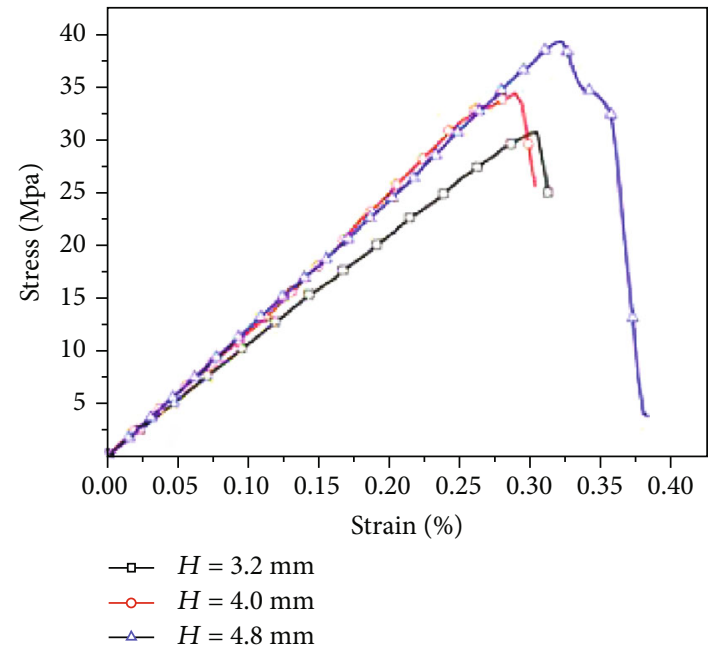

(b) Radial shear stress-strain

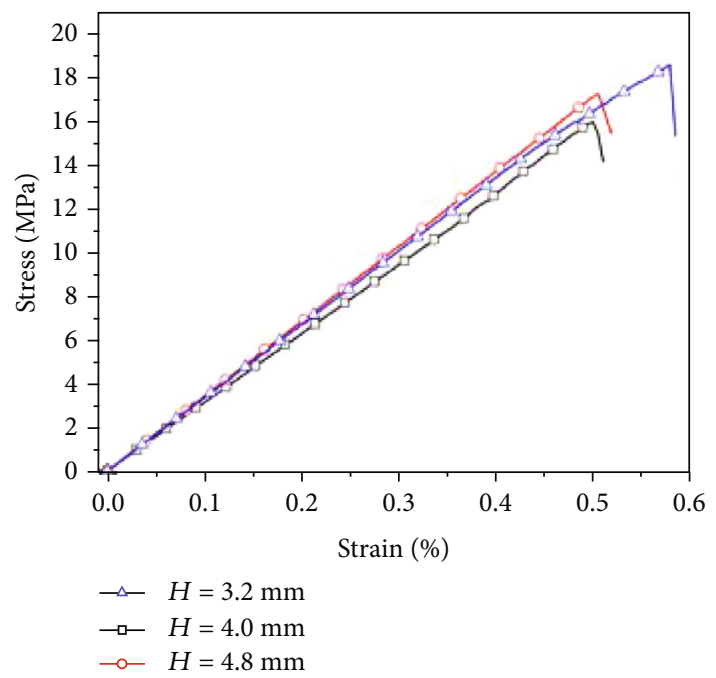

(d) Axial shear stress-strain

Figure 11: Shear test results.

TABLE 6: Shear mechanical properties of axial braided C/C composites.

\begin{tabular}{|c|c|c|c|c|c|}
\hline Specimen number & $S_{X Y},(\mathrm{MPa})$ & $G_{X Y},(\mathrm{GPa})$ & Specimen number & $S_{\mathrm{ZX}},(\mathrm{MPa})$ & $G_{Z X},(\mathrm{GPa})$ \\
\hline SXY48 & 39.2 & 12.6 & SZX48 & 18.5 & 3.4 \\
\hline SXY40 & 34.2 & 11.8 & SZX40 & 17.2 & 3.5 \\
\hline SXY32 & 30.5 & 10.7 & SZX32 & 15.9 & 3.2 \\
\hline
\end{tabular}

When compressed, the axial braided $\mathrm{C} / \mathrm{C}$ composite exhibits plastic characteristics. The radial compression sample was cut along a 45-degree bevel, and the crack was delaminated along the interlayer interface of the fiber bundle. The axial compression curve is in the form of double fold, the axial fiber rod is unstable, and the transverse fiber bundle is cut. The form of the compression failure indicates that the matrix performance and interlaminar inter- face performance and fiber bundle are the main control factors of radial compression. The main control factors of axial compression performance are the compressive strength and matrix strength of the fiber rod. The radial compression strength, compression modulus, and Poisson's ratio were $90.6 \mathrm{MPa}, 20.9 \mathrm{GPa}$, and 0.28 , respectively. The corresponding axial compression parameters are 132.5 MPa, 22.1 GPa, and 0.09. 
In the case of in-plane shear, the radial direction shows the fracture and pulling of the fiber bundle, and the material has the characteristics of pseudoplasticity. The axial direction shows brittle fracture and the fiber rod is cut. The shear strength and modulus in the radial plane were $39.2 \mathrm{MPa}$ and 12.6 GPa, respectively. The shear strength and modulus in the axial plane were $18.5 \mathrm{MPa}$ and $3.4 \mathrm{GPa}$, respectively.

With the increase of sample thickness, the strength of this material in all directions increases, but the modulus changes are not regular. The increase in strength is caused by the reduction of processing damage to the sample when the sample is large. The strain used in modulus calculation is the wholefield average of the surface strain of the sample, which is only affected by the fiber content in the sample and the test error.

(4) The above macroscopic mechanical experiments show that the reinforcement of the fiber $\mathrm{rod} / \mathrm{matrix}$ interface and fiber bundle/matrix interface can enhance the tensile strength and radial compression strength of the material. Increasing the transverse shear strength of the fiber rod can increase the axial shear strength of the material. The radial shear strength of the material can be increased by increasing the fiber bundle/matrix interface strength

\section{Data Availability}

As most of the data in this manuscript were related to trade secrets, I cannot provide them completely. In the future, if necessary, I can share some data with reviewers or readers.

\section{Conflicts of Interest}

The authors declare that there is no conflict of interest regarding the publication of this paper.

\section{Acknowledgments}

This article was funded by the Xi'an Jiaotong University, China.

\section{References}

[1] C. Wang, M. Tang, W. Liu, and T. Zhu, "Study on microstructure characteristics of axially braided carbon/carbon composites based on SEM and micro-CT," Materials, vol. 13, no. 6, p. 1414, 2020.

[2] C. Wang, P. Cao, M. Tang, W. Tian, K. Liu, and B. Liu, "Study on properties prediction and braiding optimization of axial braided carbon/carbon composite," Materials, vol. 13, no. 11, p. 2588, 2020.

[3] C. Zhang and X. Xu, "Finite element analysis of 3D braided composites based on three unit-cells models," Composite Structures, vol. 98, no. 3, pp. 130-142, 2013.

[4] P. Turner, T. Liu, and X. Zeng, "Collapse of 3D orthogonal woven carbon fibre composites under in-plane tension/compression and out-of-plane bending," Composite Structures, vol. 142, pp. 286-297, 2016.

[5] N. Castaneda, B. Wisner, J. Cuadra, S. Amini, and A. Kontsos, "Investigation of the Z-binder role in progressive damage of
3D woven composites," Composites Part A: Applied Science and Manufacturing, vol. 98, pp. 76-89, 2017.

[6] R. Gerlach, C. R. Siviour, J. Wiegand, and N. Petrinic, "Inplane and through-thickness properties, failure modes, damage and delamination in 3D woven carbon fibre composites subjected to iMPact loading," Composites Science and Technology, vol. 72, no. 3, pp. 397-411, 2012.

[7] J. Pan, Microstructure model of composites and related material properties, Yanshan University, 2018.

[8] B. Gao, T. Min, Y. Yang, and H. Shi, "Mechanical experiment of $4 \mathrm{D}$ in-plain C/C composites," Fuhe Cailiao Xuebao(Acta Materiae Compositae Sinica), vol. 28, no. 6, pp. 245-250, 2011.

[9] Z. Junjun, Investigation of Mechanical Properties of 3D Braided Composites Based on Multi-scale Theory, Harbin University of Science and Technology, 2018.

[10] R. K. Gideon, B. Sun, and B. Gu, "Mechanical behaviors of four-step $1 \times 1$ braided carbon/epoxy three-dimensional composite tubes under axial compression loading," Polymer Composites, vol. 37, no. 11, pp. 3210-3218, 2016.

[11] Z. Liu, D. Li, F. Zhang, and Y. Huang, "Numerical prediction for the elastic properties of 3D 4-directional braided composites considering adhesive layers," Acta Materiae Compositae Sinica, vol. 28, no. 6, pp. 223-229, 2011.

[12] F. Zhang, Y. Wan, B. Gu, and B. Sun, "Impact compressive behavior and failure modes of four-step three-dimensional braided composites-based meso-structure model," International Journal of Damage Mechanics, vol. 24, no. 6, pp. 805827, 2015.

[13] C. H. Xu, D. S. Xu, L. Y. Song, and K. Xu, "Microstructure characterization from X-ray micro-tomography and tensile failure mechanism of $4 \mathrm{D}$ in-plane carbon/carbon composites," Journal of Solid Rocket Technology, vol. 36, no. 6, pp. 811-815, 2013.

[14] Z. Zhu and H. Qiang, "Forecast research on micromechanical properties of $4 \mathrm{D}$ in-plane $\mathrm{C} / \mathrm{C}$ composites basedon homogenization theory," Journal of Solid Rocket Technology, vol. 42, no. 1, pp. 92-964, 2019.

[15] B. Gao, T. Min, Y. Yang et al., "Relations between microstructure and mechanical properties of fiber/matrix interface in $4 \mathrm{D}$ in-plane C / C composites," Journal of Solid Rocket Technology, vol. 34, no. 6, pp. 777-781, 2011.

[16] Y. Zhou and W. Li, "The performance evaluation of carbon fiber and composite," Hi-Tech Fiber \& Application, vol. 39, no. 6, pp. 12-19, 2014.

[17] Z. Lifeng, S. Wang, Q. Weilin et al., "Experimental study on Interface mechanical properties of unidirectional carbon fiber composites," Mechanical Science and Technology for Aerospace Engineering, vol. 38, no. 8, pp. 1296-1300, 2019.

[18] W. Chunguang, X. Guiyang, and G. Jianliang, "Buckling instability of flexible joint under high pressure in solid rocket motor," International Journal of Aerospace Engineering, vol. 2020, 10 pages, 2020 . 